\title{
ESTUDOS
}

\section{As trocas e os desafios nas práticas de investigação}

Natercia de Souza Lima Bukowitz

Palavras-chave:

práxis pedagógica; enino

superior; educação básica.

\section{Resumo}

Apresenta por meio de narrativas de situações concretas da prática docente, a viabilidade de levar a termo, nas licenciaturas de graduação em Pedagogia, uma proposta que procure integrar ensino, prática e pesquisa e nessa articulação contribuir para a melhoria do ensino na universidade e na escola básica.

\section{Introdução}

Junho de 2003.

A forma como a professora conduziu as aulas nos permitiu vislumbrar horizontes distintos dos visualizados nas demais disciplinas do curso. Impossível esquecer a primeira aula, quando participamos de uma dinâmica com o calidoscópio e o livro Zoom (Banyai, 1995). Acho que o objetivo da disciplina Prática Pedagógica I foi atingido, qual seja o de proporcionar reflexão sobre o papel do professor e sobre a principal função da escola, que é a de educar e favorecer a aprendizagem. Repensar nossas atitudes como educadores é o ponto de partida para que a mudança possa acontecer.

Os trabalhos propostos, as observações da professora nos nossos diários de campo e os relatos pessoais de todos da turma transformavam-se em conteúdos, em temas abordados e desenvolvidos nas aulas subseqüentes. Além disso a professora nos fez perceber que a dinâmica dessas aulas poderia inspirar inovações em nossas práticas: os relatórios, os diários reflexivos e os debates sobre os textos eram algumas das tarefas possíveis de serem realizadas também com nossas crianças.

Dentro dessa proposta pude aprender, com a história do amadurecimento dos caquis, que cada um tem seu ritmo próprio de aprendizagem. Além disso consegui 'remexer o lodo submerso no fundo do lago', pude abrir-me ao novo e ao diferente.

Acredito ter-me empenhado ao máximo, participando desta enorme festa "no fundo do lago". Pena que nas outras disciplinas não haja semelhante troca de idéias e oportunidades para reflexão.

(Extraído do Relatório de Avaliação da disciplina Prática Pedagógica I, elaborado por R., aluna do Curso de Pedagogia)

As reflexões e análises contidas neste relatório final de Prática Pedagógica I identificaram-se com o pensamento da maioria dos estudantes do primeiro período de Pedagogia da Universidade Católica de Petrópolis (UCP), no final do primeiro semestre de 2003 e, juntamente com as demais avaliações elaboradas pela turma, encontram-se disponíveis nos arquivos da autora.

Este registro, introdutório ao artigo, será utilizado como aporte para explicitar o conceito de "práticas investigativas", termo mencionado no art. 2, alínea IV da Resolução CNE/CP n ${ }^{\circ}$ 1, de 18/2/2002, que dispõe sobre as Diretrizes Curriculares Nacionais. Pretende-se destacar que as noções de práxis, como concebidas por Pimenta (1995), bem como as da metodologia da pesquisa-ação, desenvolvidas por Barbier (1996) e Thiollent (2002) subjazem as concepções relacionadas com as ditas “práticas investigativas", para as quais se 
voltam os objetivos das disciplinas Prática Pedagógica I, II, III e IV e Prática Supervisionada. O componente curricular Prática Pedagógica está sendo oferecido nos quatro primeiros períodos do Curso de Pedagogia, da Universidade Católica de Petrópolis (UCP), tendo sido implementado gradativamente em nova grade, a partir do primeiro semestre de 2001.

A autora deste trabalho, na qualidade de docente da disciplina, desde sua implantação, teve a possibilidade de não apenas participar de sua concepção como também de, a cada semestre, em parceria com a primeira turma que a iniciou e com as novas turmas que vêm se sucedendo, ir acrescentando-lhe novos contornos, aproximando-a do que Imbernón (2001, p. 85) chama de "formação centrada na escola". Esta "baseia-se na reflexão deliberativa e na pesquisa-ação, mediante as quais os professores elaboram suas próprias soluções em relação aos problemas práticos que se defrontam”. Além disso, conforme explicitado por Imbernón, a formação centrada na escola "não é uma tecnologia que se pode aprender, e sim um processo de participação, envolvimento, apropriação e pertença...". É uma dinâmica impregnada de forte carga ideológica onde circulam valores, atitudes e crenças. Nessas condições a escola se constitui "como unidade básica de mudança, desenvolvimento e melhoria" (Imbernón, 2001, p. 80). Tais considerações remetem ao documento introdutório deste artigo no trecho em que R. declara, ao final do primeiro parágrafo, que "repensar nossas atitudes como educadores é o ponto de partida para que a mudança possa acontecer”. O segundo parágrafo também merece ser lembrado por destacar que os "relatos pessoais de todos da turma transformavam-se em conteúdos, em temas abordados e desenvolvidos pela professora nas aulas subseqüentes."

Os pressupostos da pesquisa-ação encontram-se alinhados com os das práticas investigativas na medida em que "os professores e professoras identificam um problema ou um tema de seu interesse a partir de uma observação ou uma conversa reflexiva" (Imbernón, 2001, p. 75), buscando eles mesmos respostas para as questões levantadas. Dessa forma trabalha-se nas disciplinas de Prática Pedagógica com propósitos semelhantes aos da pesquisa-ação, isto é, favorecendo uma geração de conhecimento dentro da ação da pesquisa, onde todos os envolvidos se beneficiam da experiência uns dos outros (Barbier, 1996). Além desses objetivos, Thiollent (2002, p. 16) salienta que na pesquisa-ação há a pretensão de elevar “o nível de consciência das pessoas e grupos considerados".

O entrelaçamento das idéias de Imbernón, Barbier e Thiollent com as das avaliações discentes da disciplina Prática Pedagógica I mostram que as críticas formuladas por Pimenta sobre a ausência de participação dos docentes nas decisões acadêmicas não servem de parâmetros para a realidade a qual se aplica este artigo. O posicionamento de Pimenta (2002, p. 107) sobre a questão é o de que:

[...] o professor ingressa em departamentos que atuam em cursos aprovados, com disciplinas já estabelecidas: recebe ementas prontas, planeja individual e solitariamente e é nessa condição que deve responsabilizar-se pela docência que exerce. Os resultados a que se chega não são objeto de estudo ou análise nem individual, nem no curso ou departamento.

Os efeitos positivos das ações que vêm sendo compartilhadas com o grupo de estudantes, pesquisados e pesquisadores dentro do presente estudo têm sido revelados e percebidos pelo interesse e envolvimento que eles demonstram ao interagirem e registrarem os avanços alcançados, tal qual descrito na Introdução.

\section{Fontes inspiradoras}

Em recentes publicações especializadas na área de educação, é possível encontrar propostas pedagógicas consideravelmente inovadoras. Trata-se aqui, em especial, das Comunidades de Aprendizagem, o que Imbernón (2003, p. 14) define como: "processo de inovação, que leva os professores e as professoras de uma escola a um trabalho de pesquisa-ação, com a finalidade de elaborar um novo projeto educativo comunitário”. Percebe-se, nessa idéia das Comunidades de Aprendizagem, que não há um caminho único para transformar contextos escolares e que essa busca deve surgir dos grupos inseridos naqueles contextos. Comunidades de 
Aprendizagem divergem, em essência, de grande parte do que vem ocorrendo no cenário educacional da contemporaneidade, como apontado por Brzezinsk e Garrido (2001, p. 95), em pesquisa abrangendo setenta trabalhos apresentados no Grupo de Trabalho de Formação de Professores, durante as reuniões anuais da Anped, no período de 1992-1998: "apesar dos contínuos aportes visando à melhoria dos cursos de formação inicial dos professores, esses cursos têm sido continuamente questionados". Além disso, os dados analisados revelaram não apenas "o predomínio de práticas fundadas na concepção de ensino como transmissão" como também "a existência de contradições entre a proposta curricular e as práticas de formadores e de licenciandos” (Brzezinsk, Garrido, 2001, p. 84).

Essas referências servem para mostrar os desníveis observados em diferentes realidades: embora se reconheça a enorme variedade e fecundidade de idéias publicadas sobre a temática educacional, detecta-se nas universidades e nas unidades escolares a predominância de uma pedagogia bastante conservadora que "enfatiza a técnica e a passividade” (Giroux, 1997, p. 33).

Parece que a tentativa de inserir gradativamente a universidade nas carências e interesses da comunidade tem-se consolidado apenas em iniciativas de grupos isolados, como a relatada sobre Comunidades de Aprendizagem e na letra dos mais contemporâneos documentos legais (LDB, Lei no 9.394/96, Resolução do CNE/CP n ${ }^{\circ} 1$ de 18/2/2002, Resolução $\mathrm{CNE} / \mathrm{CP} \mathrm{n}^{\circ} 2$, de 19/2/2002). Nesses textos, nota-se uma característica comum: a de enfatizar e considerar a prática como o espaço de validação da teoria. Sendo assim, a universidade, ocupando o lugar da formação dos professores, seria espaço para reconhecimento dos saberes que partindo da prática, vão à teoria e retornam à prática.

O substrato da noção práticas investigativas, além de estar presente na Resolução CNE/CP $\mathrm{n}^{\circ}$ 1, de 18/2/2002 em seus artigos $3^{\circ}$, inciso III e $13, \S 1^{\circ}$, ancorou-se inicialmente em Dewey, desenvolvendo-se posteriormente com Zeichner (1983). Contribuindo para a evolução dessa noção, tem-se com Imbernón (2001, p. 74) "a defesa de um modelo investigativo ou de pesquisa" estrategicamente essencial à formação do professor. Caracteriza-se como u m processo em que os próprios professores "problematizam temas de sua prática, a partir das observações e reflexões sobre suas ações" no cotidiano escolar, buscando eles mesmos encontrar soluções para os problemas do ensino.

Zeichner (1999, p. 129) propõe um trabalho integrador entre escola e comunidade, fundamentado em "sensibilizar professores para valores, tipos de vida e culturas diferentes das suas, e em desenvolver o respeito pela diversidade humana”. Esta é uma questão por demais complexa e relevante num país como o Brasil, caracterizado por vastíssima extensão territorial e pluralidade cultural. Paulo Freire (1970, p. 39) compreendeu toda essa complexidade, alertando para a necessidade da libertação da força domesticadora dessa realidade opressora:

[...] a realidade social, objetiva, que não existe por acaso, mas como produto da ação dos homens, também não se transforma por acaso. Se os homens são os produtos desta realidade e se esta, na "invasão da práxis", se volta sobre eles e os condiciona, transformar a realidade opressora, é tarefa histórica, é tarefa dos homens.

Em relação à atuação dos docentes, Tardif (2002, p. 239) aproxima-se das idéias de Freire, propondo uma expressiva alteração nas concepções e nas práticas de pesquisa atualmente em vigor. Essas novas formas de pesquisa (pesquisa-ação, pesquisa colaborativa, pesquisa em parceria), possibilitam aos professores de profissão "se apropriarem da pesquisa e aprenderem a reformular seus próprios discursos, perspectivas, interesses e necessidades individuais ou coletivas em linguagens suscetíveis de uma certa objetivação”. Caracterizam-se essas novas formas de atuação pedagógica, sobretudo pelos seguintes aspectos:

- O objeto de estudo deverá convergir para a problemática suscitada pelo grupo de pesquisa, considerado também "pesquisador".

- O planejamento e objetivos da investigação, passíveis de transformações ao longo da pesquisa, serão elaborados em conjunto com o grupo. Pretende-se, com isso, gerar conhecimento dentro da ação da pesquisa na qual todos os envolvidos beneficiar-seão das experiências uns dos outros (Thiollent, 2002, p. 52). 
- Nas discussões de grupo, os dados serão conhecidos e analisados buscando redefinir o problema e encontrar soluções.

\section{Despertando o olhar da investigação: 0 zoom e o calidoscópio}

Na formação de professores, os currículos devem considerar a pesquisa como princípio cognitivo, investigando com os alunos a realidade escolar, desenvolvendo neles essa atitude investigativa em suas atividades profissionais e assim tornando a pesquisa também princípio formativo na docência (Pimenta, Severino, 2002, p. 17).

O pensamento desses dois autores fundamenta e encoraja a continuidade do tratamento metodológico que vem sendo dado não apenas às disciplinas Prática Pedagógica, mas também à de Prática Supervisionada, no Curso de Pedagogia da UCP. No caso específico da primeira, por ocasiáo da elaboração da ementa, esta recebeu a contribuição dos professores convocados para assumi-la no primeiro semestre de 2001. Dentre estes, poucos são os professores que têm tido a oportunidade de materializá-la e de dar prosseguimento ao que planejaram, seja devido a impedimentos burocráticos, seja por que não se empenharam ou não estiveram convictos o bastante acerca das possibilidades transformadoras da proposta. Tal afirmação encontra-se apoiada no testemunho de estudantes que, cursando a disciplina com diferentes professores, emitiram opiniões a respeito, verbalmente ou em avaliações escritas.

De acordo com o que foi definido pelos professores que elaboraram a ementa, deve haver no primeiro período "a problematização de um tema para investigação da prática pedagógica”. Os caminhos utilizados para provocarem essa "problematização" são distintos e em geral ligam-se às características pessoais e profissionais de cada docente, além de estarem norteados por variados comprometimentos éticos, ideológicos e filosóficos. No caso particular da Prática Pedagógica I, busca-se despertar o olhar da investigação e sensibilizar o grupo para as múltiplas dimensões da pesquisa. Desenvolve-se, a partir de um momento de sensibilização, uma dinâmica idealizada por La Cava
(2001) em que são utilizados o calidoscópio e o livro Zoom, obra já mencionada na abertura deste trabalho. O Zoom é um livro sem palavras, podendo ser "lido" tanto de frente para trás como de trás para frente. "As ilustrações saltam aos olhos como se o espectador tivesse se afastado rapidamente de cada página”. Possibilita mudar o entendimento a respeito de tudo o que se vê, "pois nada é o que parece ser". Por conseguinte, é uma atividade que favorece a mudança de paradigmas e a aceitação do confronto de diferentes pontos de vista.

Essa metodologia, combinada com a observação, no calidoscópio, das figuras que se formam e se modificam a cada mexida do observador, conferem à disciplina Prática Pedagógica I, feições especiais: torna-se crucial essa prática para que o grupo se perceba motivado para a pesquisa e inserido num processo de mudança. Nos encontros que se seguem, os relatos e as leituras de passagens dos diários de campo dos estudantes fazem emergir novos temas para discussão e estudo, ensejando a escolha de textos e vídeos que passam a ser oferecidos à turma para pesquisa e aprofundamento dos problemas apontados pelos participantes nos debates. Nesse sentido, a interação que se estabelece evoca o Círculo de Cultura, de Freire, consubstanciando as teses também defendidas por Barbier, Thiollent e Imbernón acerca da metodologia da pesquisa-ação.

Para os Círculos de Cultura, sugere Freire (1967, p. 103) que:

Em lugar de professor, com tradições fortemente "doadoras", o coordenador de debates. Em lugar de aula discursiva, o diálogo. Em lugar de aluno, com tradições passivas, o participante de grupo. Em lugar de programas alienados, programação compacta, "reduzida" e "codificada" em unidades de aprendizado.

\section{As trocas: um relato sobre o amadurecimento dos caquis e do lodo do fundo do lago}

Nos encontros iniciais com essa turma de Prática Pedagógica I predominavam situações que em muito se assemelhavam ao processo catártico: a turma se compunha, na maioria, de professores que exercem o magistério há longa data, chegaram à universidade trazendo considerável bagagem de experiências. Mas as frustrações trazidas 
sobretudo devido ao fracasso do sistema escolar, se sobrepõem aos demais problemas abordados. A rotina, característica da prática desses alunos-professores, encarrega-se de suprimir-lhes a capacidade de reflexão e de inovação. Assim é que declaradamente se expressam, pretendendo encontrar nos professores e nas aulas da Universidade, soluções para os problemas que os angustiam e inquietam (é grande a expectativa por receitas e fórmulas mágicas que solucionem as dificuldades do contexto escolar). Ao lhes ser oferecida a oportunidade de problematizar um tema para pesquisa, ocorre a catarse: entregamse às lamúrias pelos atropelos e vicissitudes do cotidiano escolar, quase sempre se eximindo da responsabilidade pelas transformações que poderiam implementar na prática docente.

Nessas ocasiões, o envolvimento, a habilidade e a capacitação do professor são essenciais para conduzir o processo de exame das situações, de redefinição dos problemas e da busca por soluções. Num desses "círculos de cultura”, F., um dos alunos-professores, queixava-se da dificuldade em alfabetizar sua turma, a seu ver, por demais heterogênea. Expressava-se enfaticamente sobre o que considerava ser fundamental: que todas as crianças estivessem prontas para aprender a ler e a escrever, e no mesmo nível de desenvolvimento. F. reforçou seus argumentos acrescentando: "Muitas das crianças não estiveram na pré-escola, estão vindo de casa e não sabem nem segurar o lápis”.

A metáfora do "amadurecimento dos caquis", citada na introdução do trabalho, funcionou como intervenção naquele momento, oferecendo ao grupo oportunidades de reflexão acerca da "heterogeneidade das turmas". Além disso, esclareceu como esta problemática pode ser encarada pelos professores diante do compromisso com a aprendizagem dos alunos. A concretude e a verossimilhança da história dos caquis foram fundamentais para a sustentação de argumentações a favor de um ensino que respeite as hipóteses do aluno sem, contudo, constrangê-los ou agredi-los em suas crenças. A metáfora dos caquis permeou as reflexões do grupo na maior parte do tempo do semestre, encaixandose no contexto principalmente porque emergiu de uma situação real ocorrida simultaneamente aos questionamentos de
F. A história sucedeu à autora deste artigo, como relatado a seguir:

Fui presenteada com aproximadamente 50 caquis, todos igualmente verdes na aparência. Na primeira semana continuaram verdes. Depois da primeira semana alguns poucos caquis começaram a mostrar sinais de amadurecimento. A cada semana aconteciam pequenas modificações nas frutas, mas não eram uniformes. A prontidão para que estivessem comíveis não foi simultânea, foi gradativa e diferenciada. Todos eram frutos da mesma árvore e haviam sido colhidos no mesmo dia. Passou-se mais de um mês para que os últimos caquis pudessem ser finalmente ingeridos.

As notícias sobre o que estava acontecendo com os caquis iam sendo reveladas ao grupo a cada encontro, propiciando novas discussões e debates. Esses debates remeteram a estudos em textos de Piaget, Emilia Ferreiro e de outros pesquisadores, solicitados pelos próprios alunos da turma. Esses estudos visaram explicar e aprofundar as questões suscitadas, relativas às dificuldades de aprendizagem das crianças, relacionadas com o desconhecimento dos professores acerca da existência dos diferentes estágios do desenvolvimento infantil.

A utilização dessa história, como possibilidade de mediação entre os conhecimentos científicos que deverão estar incorporados aos saberes desses professores na busca de caminhos para a efetiva aprendizagem de seus alunos, alcançou expressivo significado - embora 90\% dos integrantes da turma tenham obtido certificação no Curso de Formação de Professores e atuem, há vários anos, na Educação Infantil ou Fundamental, vale registrar a colocação de F. após exaustivas discussões sobre o tema dos desníveis nas turmas: "Mas professora, até quando vou ter que esperar que amadureçam?"

Sobre essa questão Tardif (2002) esclarece que:

Uma abordagem tipológica baseada na proveniência social dos saberes parece ser relativamente simplificadora, pois dá a impressão de que todos os saberes são, de um certo modo, contemporâneos uns dos outros e imóveis e encontram-se igualmente disponíveis na memória do professor, o qual buscaria nesse "reservatório de conhecimentos" aqueles que lhe são necessários no momento da presente ação (p. 67). 
Para Tardif os saberes dos professores encontram-se muito mais vinculados às suas histórias de vida, principalmente no que diz respeito aos anos de permanência no ambiente escolar e às práticas ali desenvolvidas, tendendo a repeti-los, do que aos ensinamentos específicos oferecidos nos cursos de formação.

É essa complexa rede de relações que permite compreender os embates com os quais deverão lidar esses graduandos, sujeitos/participantes e público-alvo da presente discussão, diante dos desafios diários da sala de aula, pois mesmo que em sua trajetória de estudantes tenham aprendido sobre epistemologia, infância, e aprendizagem, estes conhecimentos tornam-se meras reminiscências, merecendo ser retomados e rediscutidos mediante o surgimento de novas situações-problema. Nesse sentido, cabe alertá-los sobre a relevância da investigação permanente sobre a prática, e da reflexão crítica sobre ela, de "remexer o lodo e o lixo submersos sob a aparência das límpidas e serenas águas de um lago”. O forte simbolismo contido nessa metáfora fez que repercutisse positivamente sobre todos do grupo em análise, sinalizando para eles a possibilidade histórica de assumirem a autoria de suas práticas. Colocando-se no fundo do lago, removendo o lodo estagnado e solidificado de práticas herdadas, estarão próximos dos objetivos traçados por Tardif (2002, p. 237) para que os professores tornem-se sujeitos de seu conhecimento: "seu trabalho cotidiano não é somente um lugar de aplicação de saberes produzidos por outros, mas também um espaço de produção, de transformação e de mobilização de saberes que lhe são próprios”.

\section{Uma experiência desafiadora: a práxis incompreendida}

Referir-se aos desafios que se colocam aos educadores empenhados na transformação exige discutir previamente a abrangência e o poder de disseminação das idéias que, embutidas nas linhas e entrelinhas dos preceitos legais, interferem nas ações e decisões cotidianas das instituições de ensino. No entanto, é preciso mostrar que a observância dessas regras pode compatibilizar-se com uma postura pedagógica calcada na crítica, na reflexão e na investigação. Veiculada pelo movimento neoliberal, instaurou-se nas políticas educacionais contemporâneas, uma tendência caracterizada pelo retorno ao tecnicismo, sendo possível observar seu célere avanço, em todos os níveis de ensino. Sobre essa questão, Silva (2003, p. 299) pronuncia-se alertando para os riscos da submissão da educação aos apelos do mercado, na qual sobressai a cisão entre a reflexão e a ação:

O Banco Mundial chega ao interior das escolas públicas por meio de programas, projetos e planos elaborados por seus técnicos e conselheiros [...], separando o pensar e o fazer. A comunidade escolar é apenas informada sobre os programas, projetos e planos, recebendo orientações necessárias ao preenchimento de formulários e à prestação de contas. A reflexão sobre o trabalho pedagógico diluiu-se em meio a tantos procedimentos burocráticos a serem cumpridos.

Pretende-se com estas discussões destacar a relevância de uma proposta que incentive e encoraje os professores a criar e adotar metodologias diferenciadas para ensinar e aprender, partindo de observações dos alunos e de uma atitude investigativa.

Embora admitida a complexidade do mundo contemporâneo e das instituições nele inseridas, a intervenção de um sistema regulador que as protejam faz-se necessária, permitindo que funcionem de maneira organizada. Dessa forma, entende-se que à lei cabe a função de normatizar, de regulamentar o que a sociedade, por meio de seus atores e de um processo de evolução e maturação, exige e deseja ver consolidado. Nesse sentido pensa-se na lei como o resultado de ações e reflexões sobre as relações estabelecidas entre seres humanos, e, portanto, éticas e passíveis de superações e alterações. Sendo fruto de elaborações da mente humana, a partir das interações nas práticas sociais, devem estar a serviço da sociedade, não para subjugá-la ou aprisionála. Ancorar a docência responsável, construtiva e criativa tão-somente no que determinam os documentos legais ou nas prescrições de organismos internacionais pode não bastar aos educadores que verdadeiramente se comprometem com a visão transformadora da práxis.

A noção de práxis, longe de conflitarse com a da "norma", pode, ao contrário, ser entendida a partir de uma mesma ótica já que ambas, práxis e "norma”, derivam da movimentação e da invenção tipicamente 
humanas. Contribui para esta linha de pensamento o conceito de práxis apresentado por Pimenta (2002, p. 216):

Práxis: ação (motora, perceptiva, reflexiva) do sujeito sobre o objeto a ser conhecido. Toda a aprendizagem é ativa, exige essa ação, que também possibilita a articulação do conhecimento com a prática social que lhe deu origem.

Subjacente a esta concepção situa-se uma visão dialética de educação, na qual teoria e prática encontram-se em permanente diálogo. $\mathrm{Na}$ esteira dessas tendências dialéticas ancoram-se os textos das legislações concernentes às práticas investigativas.

Assim é que, de acordo com a Resolução CNE/LP n ${ }^{\circ} 1$ de 18/2/2002, que institui as Diretrizes Curriculares Nacionais para a Formação de Professores da Educação Básica, em nível superior, curso de licenciatura, de graduação plena, "a prática deverá estar presente desde o início do curso e permear toda a formação" (art. 12 , $2^{\circ}$ ). Diz ainda o mesmo documento em seu art. 15 que "os cursos de formação de professores que se encontram em funcionamento deverão se adaptar a esta Resolução, no prazo de dois anos”. Dessas determinações depreende-se que em muitos dos Cursos de Pedagogia, estruturados curricularmente na vigência da legislação que antecedeu à Resolução CNE/ LP $n^{\circ} 1$ de 18/2/2002, os estágios continuam a ser oferecidos somente nos últimos períodos do curso, o que obrigatoriamente não os impedirá de estarem em consonância com orientações mais inovadoras. Pimenta (1995, p. 122) já defendia a idéia do Estágio como um componente do currículo que não se configura como disciplina e sim "como atividade instrumentalizadora da práxis (atividade teórica e prática) educacional, de transformação da realidade existente".

Os procedimentos inerentes à disciplina Prática Supervisionada, sob a responsabilidade da autora deste texto já vêm, há vários anos, transitando pelos caminhos apontados por Pimenta, sendo orientados no sentido de contemplar a escola como um contexto a ser repensado e modificado, mesmo nas turmas ainda sob a vigência da antiga legislação. Trabalha-se nessas turmas de modo a evitar que o estágio tãosomente sintetize a aplicação da teoria estudada nas diferentes disciplinas do curso. A empreitada tem sido desafiadora: apesar de toda a preparação, investimento e provocação, nem todos os graduandos são permeáveis à proposta. Os enfrentamentos podem ser notados examinando-se situações como a que vem relatada a seguir:

Outono de 2003.

Observando a turma onde A. estagiava percebi crianças que ainda não haviam construído o conceito de número, tal como pesquisado por Kamii (1990). No recreio conversei com A. sobre o fato de as escolas, na maioria dos casos, ocuparem-se com "atividades em si mesmas", descoladas de sua fundamentação, desatreladas dos alcances educacionais que delas deveriam advir. Lembrei-me de Giroux (1997), referindo-se "aos professores como executores de tarefas", porque A. deixou de realizar as intervenções que seriam essenciais ao estágio, de forma a reconduzir a aprendizagem de grande parte das crianças da turma. Como A. apenas cumpria as tarefas programadas, retornei a ela minhas apreciações a respeito, procurando agir de forma ética e amigável. Sugeri que observasse cada criança, procurando atendê-las em suas necessidades e dessa forma não só eles aprenderiam mas também ela, revendo sua prática. Por considerar a situação propícia ao crescimento de todos da turma de Prática Supervisionada, pedi a autorização de A. para que este episódio se transformasse no tema da aula seguinte. Com a anuência de A., pedi-lhe que expusesse às colegas as experiências do estágio. A. surpreendeu-me expressando sentimentos de insegurança, embaraço e desconforto por ter sido "observada" no estágio. Além disso, mostrou-se indignada perante às indagações formuladas afirmando que estas "soavam como um interrogatório”. A. não conseguiu alcançar a significância e a relevância de um trabalho comprometido com a noção da práxis e nem mesmo a do papel do professor supervisor do estágio. Contudo, ao término do estágio, A. admitiu em seu relatório final, que:

[...] os processos mentais básicos para a matemática necessitam ainda ser muito trabalhados com esta turma para que certos conceitos sejam efetivamente cons-truídos. Há necessidade da quantificação ser revista todo o tempo através de objetos que eles próprios manuseiem. Admito que os professores se preocupam mais com o conteúdo e com o que deve ser mostrado aos pais do que com a aprendizagem

Este repensar atenuou, em parte, os equívocos e constrangimentos ocorridos. Nossas 
trocas não deixaram de ser frutíferas e de atingir objetivos. Pude extrair dessa experiência que as lições da "práxis" nem sempre são bem-vindas, benfazejas ou as almejadas pelos que se lançam e se aventuram nas utopias.

(Diário Reflexivo ${ }^{1}$ da Autora)

\section{Considerações finais}

As reflexões sobre as questões levantadas pelos alunos-professores, nas práticas investigativas, somaram-se à contribuição dos demais autores/parceiros nesta construção coletiva, permitindo concluir que os chamados e provocações dos movimentos educacionais mais ousados, renovadores e promissores não conseguem atingir a todos. As resistências dos professores provêm das mais variadas direções, impedindo-os de vislumbrar que remexer o lodo pode ser uma "grande festa" a ser desfrutada no fundo do lago... para estes talvez seja mais vantajoso manterem-se presos ao lodo!

\section{Referências bibliográficas}

BANYAI, Istvan. Zoom. Tradução de Gilda Aquino. Rio de Janeiro: Brinque - Book, 1995.

BARBIER, René. A pesquisa-ação. Tradução da professora Lúcia Lídio. Paris: Ed. Economica, 1996. Mimeografado. Título original: La Recherche Action.

BRASIL. Lei $\mathrm{n}^{\circ}$ 9.394, de 20 de dezembro de 1996. Estabelece as Diretrizes e Bases da Educação Nacional. Diário Oficial da União, Brasília, 23 dez. 1996.

. Resolução do CNE/CP no 1 de 18 de fevereiro de 2002. Institui Diretrizes Curriculares Nacionais para a Formação de Professores da Educação Básica, em Nível Superior, curso de licenciatura, de graduação plena. Diário Oficial da União, Brasília, 4 mar. 2002. Seção 01, p. 9.

. Resolução CNE/CP n ${ }^{\circ} 2$ de 19 de fevereiro de 2002. Institui a duração e a carga horária dos cursos de licenciatura, de graduação plena, de Formação de Professores Educação Básica, em Nível Superior. Diário Oficial da União, Brasília, 4 mar. 2002. Seção 01, p. 9.

BRZEZINSK, Iria; GARRIDO, Elsa. Análise dos trabalhos do GT Formação de Professores: o que revelam as pesquisas do período 1992-1998. Revista Brasileira de Educação, n. 18, set./dez. 2001.

FREIRE, Paulo. Educação como prática da liberdade. Rio de Janeiro: Ed. Civilização Brasileira, 1967.

Pedagogia do oprimido. Rio de Janeiro: Paz e Terra, 1970.

GIROUX, Henry. Os professores como intelectuais: rumo a uma pedagogia crítica da aprendizagem. Porto Alegre: Artes Médicas, 1997.

IMBERNÓN, Francisco. Formação docente e profissional: formar para a mudança e a incerteza. São Paulo: Cortez, 2001.

As comunidades de aprendizagem e o novo papel do professor. Pátio Revista Pedagógica, v. 6, n. 24, p. 14-17, nov. 2002/jan. 2003.

KAMII, Constance. A criança e o número. Campinas: Papirus, 1990.

\begin{tabular}{c}
\hline Documento inspirado em Schön \\
(1997, p. 83) segundo o qual, \\
"após a aula, o professor pode \\
pensar no que aconteceu, no que \\
observou, no significado quelhe \\
deu e na eventual adoção de ou- \\
tros sentidos. Refletir sobre a \\
reflexão-na-ação é uma ação, \\
uma observação e uma descri- \\
ção que exige o uso de palavras".
\end{tabular} 
LA CAVA, Sandra. Documento norteador da Proposta Pedagógica do Município de Petrópolis. Petrópolis: Secretaria de Educação e Esportes, 2001.

PIMENTA, Selma Garrido; ANASTASIOU, Léa das Graças C. Docência no ensino superior. São Paulo: Cortez, 2002. 1995. . O estágio na formação de professores: unidade teoria e prática? São Paulo: Cortez,

SILVA, Maria Abádia da. Do projeto político do Banco Mundial ao projeto político pedagógico da escola brasileira. Caderno Cedes, Campinas, v. 23, n. 61, p. 283-301, dez. 2003.

TARDIF, Maurice. Saberes docentes e formação profissional. Petrópolis: Vozes, 2002.

THIOLLENT, Michel. Metodologia da pesquisa-ação. São Paulo: Cortez, 2002.

SCHÖN, Donald A. Formar professores como profissionais reflexivos. In: NÓVOA, Antonio (Coord.). Os professores e a sua formação. Lisboa: Publicações Dom Quixote, 1997.

ZEICHNER, Ken. Novos caminhos para o practicum: uma perspectiva para os anos 90 . In: NÓVOA, Antonio (Coord.). Os professores e sua formação. Lisboa: Publicações Dom Quixote, 1997.

Natercia de Souza Lima Bukowitz, mestre em Educação pela Universidade Católica de Petrópolis (UCP), é doutoranda em Educação pela Universidade Federal do Rio de Janeiro (UFRJ) e professora do Curso de Pedagogia da UCP e da Universidade Estácio de Sá (Unesa).

nbkw@globo.com

\section{Abstract}

This article points out, by means of narrating concrete situations in teaching practice, that it is possible to consider, in Pedagogy licensing, a proposal which attempts to integrate instruction, experience and research, and in such an articulation, to contribute for an improvement in teaching at universities and at elementary schools as well.

Keywords: praxis; active research; inquiry practice.

Recebido em 4 de dezembro de 2003.

Aprovado em 24 de maio de 2004. 